\title{
A Rare Case of Gaint Cell Tumour of Distal Femur with Intra- Articular Extension
}

\author{
Dr. Prashant Kamble
}

\begin{abstract}
A 25 year old male patient, farmer presented with symptoms of pain, swelling and restricted right knee movements since 6 months. Range of motion was severely restricted with fixed flexion deformity of 20 degrees. X-ray of knee (anterior posterior and lateral view) showed osteolytic lesion involving distal femur with intra-articular extension and MRI showed involvement of distal $10 \mathrm{cms}$ of ephiphysiometaphyseal area of femur with focal intra-articular extension and into tibia. Biopsy was done initially following the standard principles. Histopathological report turned out to be gaint cell tumour without sarcomatous changes. The treatment options available were biological knee construction (i.e. arthrodesis with internal/external fixation and auto bone grafting) and megaprosthetic knee replacement. Excision of tumour followed by arthrodesis with custom made intramedullary interlocking nail with fibula and iliac bone grafting. Post operatively there was $2 \mathrm{cms}$ shortening was present. On 1 year follow up patient is carrying out his daily living activities and radiographs done showing good graft consolidation and without any signs of recurrence.
\end{abstract}

Key Words: Gaint cell tumour, biologic reconstruction.

\section{Introduction:}

Gaint cell tumour is one of the most common bening tumours. But they are known for recurrence and pulmonary metastasis occur in approximately 3\% cases. It constitutes $5 \%$ of all bone tumours as per western literature. It is more common in asian subcontinent. China nad india where it constitutes $20 \%$ of tumour cases. GCT most commonly occurs in third and fourth decade with its peak in third decade. Most common site being distal femur, followed by proximal tibia . In the upper limb distal end of radius is the most common site. Spinal involvement, small bones of hand and foot are rare.

Gaint cell tumour most commonly involves ephiphysis. In the skeletally immature patients occur in metaphysic. Tumour frequently breaches the cortex but intra-articular extension is rare. GCT is most common among females.

\section{Materials And Methods :}

A 25 year old male patient, farmer presented with symptoms of pain, swelling and restricted right knee movements since 6 months. Range of motion was severely restricted with fixed flexion deformity of 20 degrees with further flexion possible upto 70 degrees. On examination diffuse swelling of size $12 \mathrm{cms}$ all around the distal femur and knee. X-ray of knee (anterior posterior and lateral view) showed osteolytic lesion involving distal femur with intra-articular extension and MRI showed involvement of distal $10 \mathrm{cms}$ of ephiphysiometaphyseal area of femur with focal intra-articular extension and into tibia.

Biopsy was done initially following the standard principles. Histopathological report turned out to be gaint cell tumour without sarcomatous changes. the treatment options available were biological knee construction (i.e. arthrodesis with internal/external fixation and auto bone grafting) and megaprosthetic knee replacement. Considering his age, occupation and economic status excision of tumour followed by arthrodesis with custom made intramedullary interlocking nail with free fibula and iliac bone grafting done.

\section{Operative Procedure:}

Patient in prone position bone graft harvested from both posterior superior iliac bone. Free fibula graft length corresponding to the length of the defect harvested from opposite limb. Tumour site approached through standard anterior midline approach. Distal $10 \mathrm{~cm}$ of tumour area is excised from femur and proximal tibial portion curreted out. Stabilisation of knee done using custom made intramedullary interlocking nail with free fibula and iliac bone grafting done.

\section{Results:}

GCT is known for local reccurence and hence regular follow up is essential. Post operatively patient called up for follow up at every month for 3 months and after every 3 months. At each follow up radiographs of the operated limb and chest radiograph to look for any metastasis done. Follow up radiographs showed consolidation of bone graft and there was no signs of recurrence. 


\section{Discussion:}

GCT is an osteolytic tumour which occurs in young adults with predilecation for female sex and epiphysis. It is also called as osteoclastoma. Most of the patients presents with pain, swelling, limitation in the motion and very rarely pathological fractures.

\section{Pathology:}

Gross GCT of bone is characteristically brown, firm, friable solid mass with secondary haemorrhages. Microscopically GCT is composed of many multinucleated gaint cell as much as 40-60 nuclie per cell and stromal cells which are mononuclear spindle shaped.

\section{Plain Radiographs:}

\section{Imaging:}

GCT appears as lytic lesion involving epiphysis, eccentric and expansile mass. Apart from the thin shell of subperiosteal new bone outlining the outer surface of tumour, no periosteal reaction is appreciated.

Mri:

MRI is useful to determine the extent of the lesion within the bone and soft tissue extension. Currently this is the best imaging modality. It also is useful in differentiating from other tumours.

\section{Classification:}

Campanacci classification:

Enneking classification:

Stage 1: latent

Stage 2: active

Stage 3: aggressive

Feature corresponds to campanacci grading.

\begin{tabular}{|l|l|l|l|}
\hline FEATURE & TUMOR & CORTEX & REACTIVE BONE \\
\hline GRADE 1 & Well marginated & Intact & Present and thick \\
\hline GRADE 2 & Relatively well defined & Thin and expanded & Thin \\
\hline GRADE 3 & Fuzzy borders & Breached & Absent \\
\hline
\end{tabular}

Our patient corresponds to enniking stage 3 and campanacci stage 3 . Hence the treatment options avialble were biologic knee reconstruction (i.e. arthrodesis with internal/external fixation and auto bone grafting) and megaprosthesis knee replacement. Considering his age, occupation and economic status arthrodesis was the best option, advantage being stability and longevity. Mega prosthesis carries the advantage of stability and mobility but disadvantage being loosening and requires repeated revision.

In conclusion arthrodesis of knee with long intramedullary interlocking nail and bone grafting is an effective procedure for GCT involving intra-articular extension.
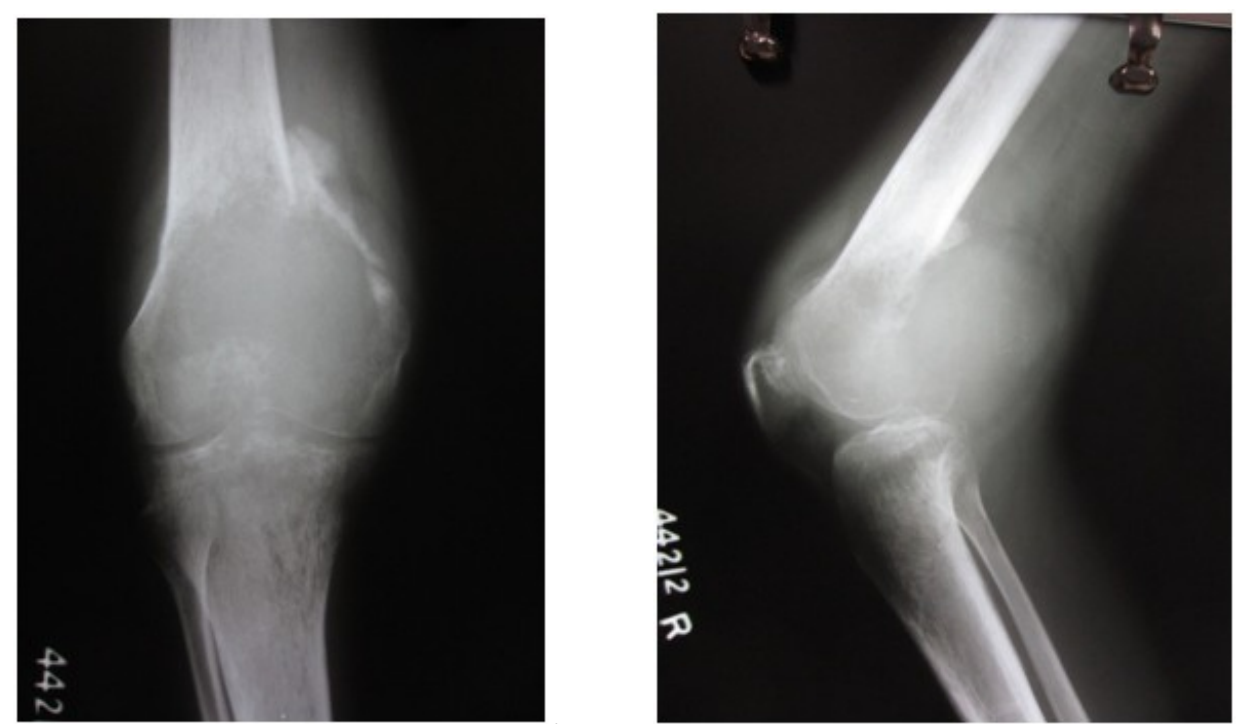

Fig 1: Pre-operative radiographs showing lytic lesion and intra-articular extension. 

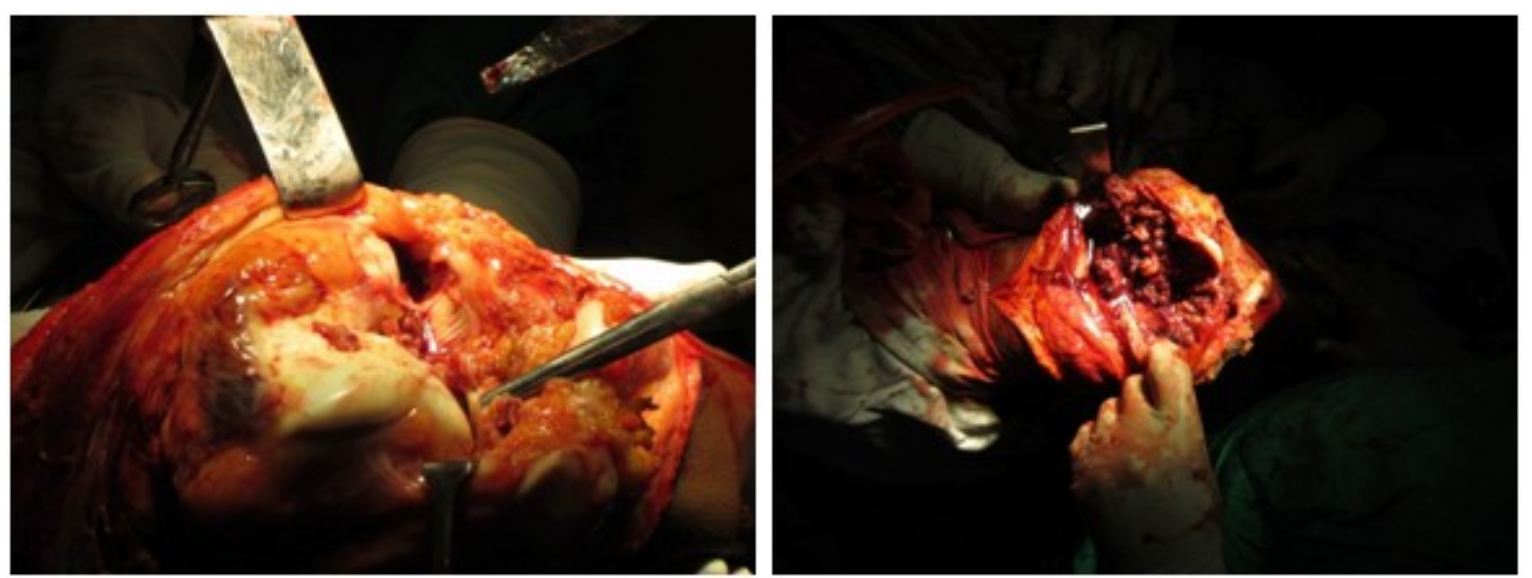

Fig.2: Intraoperative picture showing brownish friable masses and intraarticular extension with destruction of articular damage.
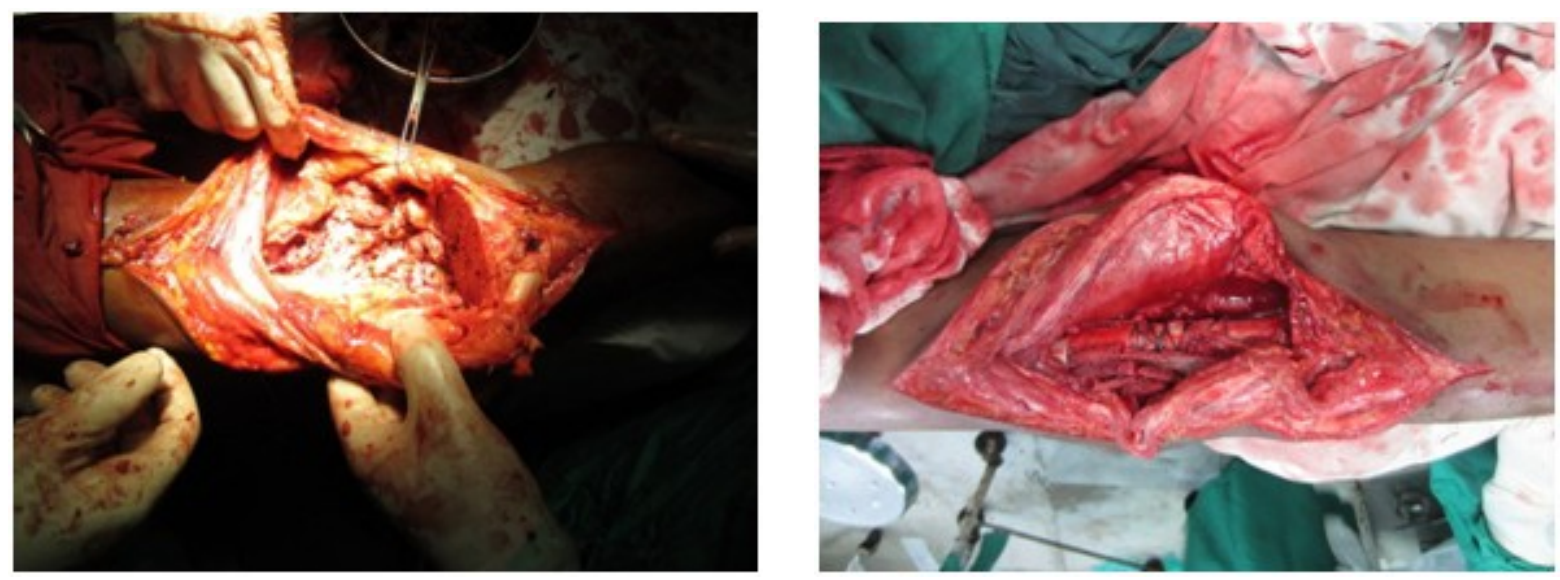

Fig.3: Intraoperative pictures after excision of tumor mass and after intramedullary nail and bone grafting.
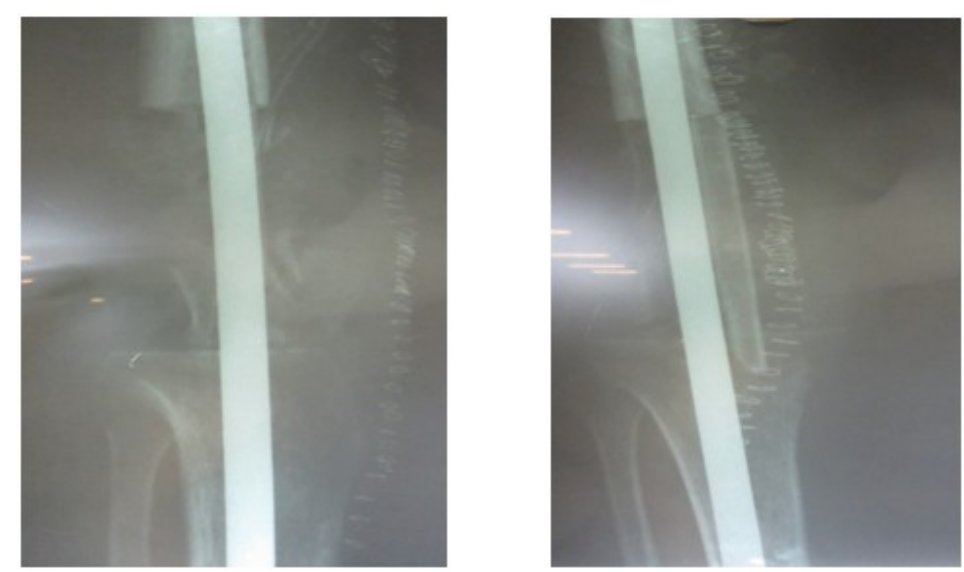

Fig.4: postoperative radiographs showing intramedullary rod and bone grafts 


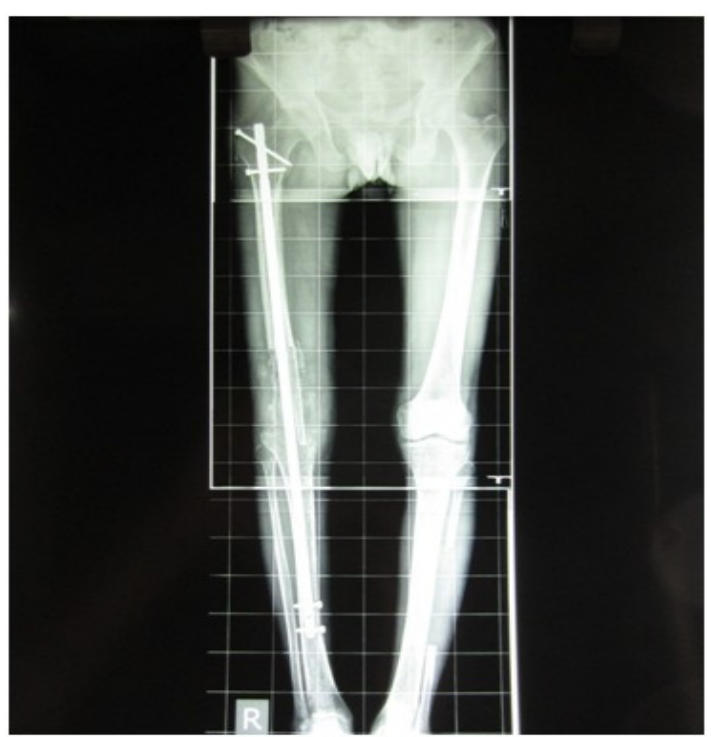

Fig.5: 1 year postoperative radiographs showing bone graft consolidation and without any signs of recurrence.

\section{References:}

[1]. Blackley et al., 1999. Blackley HR, Wunder JS, Davis AM, et al: Treatment of giant-cell tumors of long bones with curettage and bone-grafting. J Bone Joint Surg 1999; 81 A:811.

[2]. Campanacci et al., 1987. Campanacci M, Baldini N, Boriani S, et al: Giant-cell tumor of bone. J Bone Joint Surg 1987; 69A:106

[3]. Cheng et al., 2001. Cheng C, Shih H, Hsu K, Hsu R: Treatment of giant cell tumor of the distal radius. Clin Orthop Relat Res 2001; 383:221.

[4]. Forest et al., 1998. In: Forest M, Tomeno B, Vanel D, ed. Orthopedic surgical pathology: diagnosis of tumors and pseudotumoral lesions of bones and joints, Edinburgh: Churchill Livingstone; 1998.

[5]. Current concepts in Bone and soft tissue tumors: Dr Ajay puri, Dr.M.G.Aggarwal Labs et al., 2001. Labs K, Perka C, Schmidt R: Treatment of stages 2 and 3 giant-cell tumor. Arch Orthop Trauma Surg 2001; 121:83.

[6]. Nojima et al., 1994. Nojima T, Takeda N, Matsuno T, et al: Case report 869. Skeletal Radiol 1994; 23:583.

[7]. Pals and Wilkins, 1992. Pals SD, Wilkins RM: Giant cell tumor of bone treated by curettage, cementation, and bone grafting. Orthopedics 1992; 15:703.

[8]. Ward and Galaxy, 2002. Ward W, Galaxy L: Customized treatment algorithm for giant cell tumor of bone: report of a series. Clin Orthop Relat Res 2002; 397:259

[9]. Zaretski, Arik M.D.; Amir, Aharon M.D.; Meller, Isaac M.D.; Leshem, David M.D.;

[10]. Kollender, Yehuda M.D.; Barnea, Yoav M.D.; Bickels, Jacob M.D.; Shpitzer,

[11]. Thomas M.D.; Ad-El, Dean M.D.; Gur, Eyal M.D Free Fibula Long Bone Reconstruction in Orthopedic Oncology: A Surgical Algorithm for Reconstructive Options Plastic \& Reconstructive Surgery: June 2004 - Volume 113 - Issue 7 